
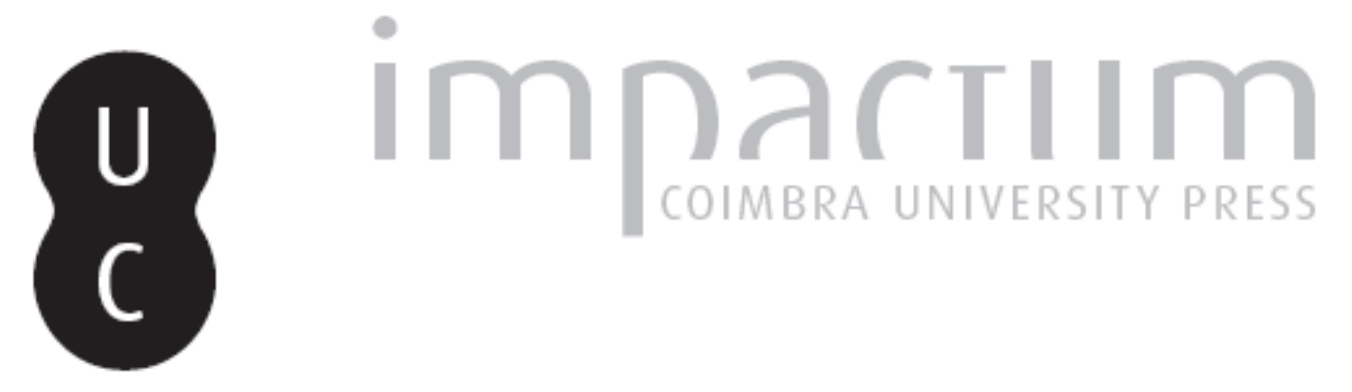

\title{
Vincitvr hic fatvs: o epitáfio métrico de Couto de Baixo
}

\section{Autor(es): $\quad$ Soares, Carmen Isabel Leal}

Publicado por: Imprensa da Universidade de Coimbra

URL persistente:

URI:http://hdl.handle.net/10316.2/45512

DOI:

DOI:https://dx.doi.org/10.14195/1647-8657_31_7

Accessed : $\quad$ 26-Apr-2023 16:29:39

A navegação consulta e descarregamento dos títulos inseridos nas Bibliotecas Digitais UC Digitalis, UC Pombalina e UC Impactum, pressupõem a aceitação plena e sem reservas dos Termos e Condições de Uso destas Bibliotecas Digitais, disponíveis em https://digitalis.uc.pt/pt-pt/termos.

Conforme exposto nos referidos Termos e Condições de Uso, o descarregamento de títulos de acesso restrito requer uma licença válida de autorização devendo o utilizador aceder ao(s) documento(s) a partir de um endereço de IP da instituição detentora da supramencionada licença.

Ao utilizador é apenas permitido o descarregamento para uso pessoal, pelo que o emprego do(s) título(s) descarregado(s) para outro fim, designadamente comercial, carece de autorização do respetivo autor ou editor da obra.

Na medida em que todas as obras da UC Digitalis se encontram protegidas pelo Código do Direito de Autor e Direitos Conexos e demais legislação aplicável, toda a cópia, parcial ou total, deste documento, nos casos em que é legalmente admitida, deverá conter ou fazer-se acompanhar por este aviso. 
FACULDADE DE LETRAS

INSTITUTO DE ARQUEOLOGIA

\section{CONIMBRIGA}

VOLUME XXXI

,

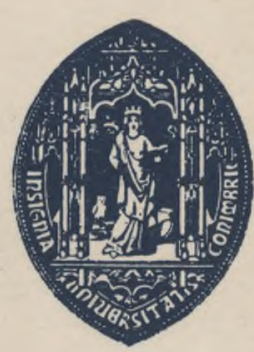

UNIVERSIDADE DE COIMBRA

1992 
CARMen IsABel LeAl SoARES

Assistente Estagiária do Instituto de Estudos Clássicos (FLUC)

\section{VINCITVR HIC FATVS}

— O EPITÁFIO MÉTRICO DE COUTO DE BAIXO

“Conimbriga", XXXI, 1992, p. 155-172

Resumo: Proveniente de Couto de Baixo (Viseu), o epitáfio dedicado a Juvêncio oferece como particularidade um carmen epigraphicum nas quatro últimas linhas. A autora analisa o interesse histórico, literário e linguístico do texto compósito (prosa e verso). Conclui-se da existência de um conhecimento literário popular (não elitista), que se configura também como um agente da romanização. Não estamos perante o testemunho de um poeta, até ao presente desconhecido. Trata-se apenas das palavras de mais um "autor de versos".

RÉsumÉ: Provenant de Couto de Baixo (Viseu), F épitaphe dédié à Juvence presente la particularité de posséder un carmen epigraphicum dans ses quatre dernières lignes. L'auteur analise l'intérêt historique, littéraire et linguistique d'un texte écrit en prose et en vers. Elle finit pour conclure sur l'éxistence d'une connaissance littéraire de caractère populaire (pas élitiste) dans laquelle on retrouve un agent de la romanisation. Il ne s'agit pas du témoignage d'un poète, mais seulement des paroles d'un "auteur de vers".

Conimbriga, 31 (1992), 155-172 
(Página deixada propositadamente em branco) 


\title{
VINCITVR HIC FATVS \\ - O EPITÁFIO MÉTRICO DE COUTO DE BAIXO
}

\author{
Dignum laude uirum Musa uetat mori
}

Hor. Carm. 4. 8, 28

Perante a morte, o homem de todos os tempos, independentemente da sua crença ou religião, não pode ficar indiferente. Para uns, ela é um fim definitivo, uma meta para além da qual nada mais existe - assim se manifestaram, na Roma antiga, o epicurismo e o estoicismo, sistemas filosóficos e vivenciais herdados da Grécia. Outros, porém, encaram-na como um bem. Constitui a passagem a uma vida melhor, mais perto da divindade - é o caso dos cultos mistéricos, do pitagorismo, do orfismo, do cristianismo.

Numa civilização preponderantemente pragmática como a romana, os valores sociais do homem - com os seus direitos e deveres enquanto membro activo da civitas - atingiram um relevo poucas vezes conseguido. O grande objectivo desse cidadão, orgulhoso do seu estatuto, foi, desde sempre, a imortalidade, a fama imorredoura. As figuras públicas pretendem assegurar a perpetuidade da sua memória gravando na pedra tumular os cargos públicos que desempenharam (políticos, militares e/ou religiosos). O homem comum partilhava da mesma ambição. Como não podia louvar uma imagem pública, que não tinha, encontrou na poesia um meio igualmente apropriado ao seu intuito.

Horácio escreveu: "Ao homem digno de louvor a Musa não deixa morrer". Este verso assumiu um significado proverbial. A poesia dá "visão" ao cego aedo, permite a realização do impossível, o amansar das feras e dos monstros dos Infernos. Mas o comum mortal não se "salva" pelo mito, nem possui a inspiração da Musa. Esta, contudo, não lhe negará 
o sonho alimentado durante uma vida inteira, ou simplesmente esboçado no leito de morte. Assim o comprova o epitáfio métrico de Juvêncio, que brilha no meio de uma epigrafia maioritariamente em prosa.

Foi nosso propósito ilustrar o modo como a epigrafia nos permite conhecer gente anónima e que, no entanto, constrói a História. Tivemos a feliz oportunidade de ver como uma cultura se adivinha por detrás de um singelo, mas tocante, epitáfio métrico $\left(^{1}\right)$.

\section{Uma ara reaproveitada em placa}

A fim de restaurar a igreja paroquial de Couto de Baixo, procedeu-se à demolição das ruínas do seu edifício original. No decurso dos trabalhos foi encontrado um bloco rectangular de mármore, que, curiosamente, apresentava inscrições funerárias em duas das suas faces.

Ao presente trabalho interessa a inscrição mais tardia e, sobremaneira, a sequência métrica das quatro últimas linhas. Serão breves, por isso, as considerações que dedicaremos à epígrafe da face frontal (Est. I, A):

(1) Dificuldades de vária ordem teriam, obrigatoriamente, de surgir quando se começa a desbravar um campo em que se tem pouca experiência. Gostaríamos, por isso, de expressar o nosso sincero agradecimento aos Senhores Professores Doutores José d'Encarnação e Walter de Medeiros, que nos dispensaram o seu avisado conselho, quando dele mais precisámos.

No decorrer do nosso trabalho utilizaremos com frequência as seguintes abreviaturas:

$\mathrm{AC}=L$ 'antiquité classique, Révue sémestrielle des Universités de Bruxelles, Gand, Liège et Louvain, Leuven, Bélgica;

CIL II = HÜBNER, Ae., Corpus Inscriptionum Latinarum - II, Berlim, 1869. Suplemento, 1892;

$\mathrm{FE}=$ Ficheiro Epigráfico. Suplemento da revista Conimbriga, Coimbra

HAE = Hispania Antiqua Epigraphica. Suplemento de Archivo Español de Arqueología, Madrid;

ICERV = VIVES, J., Inscripciones cristianas de la España romana y visigoda, Barcelona, 1942;

ILER = VIVES, J., Inscripciones latinas de la España romana, Barcelona, 1971 e 1972;

IRCP = ENCARNAÇÃO, J. d', Inscrições romanas do conventus Pacensis, Coimbra, 1984.

Conimbriga, 31 (1992), 155-172 
[D(/¿s)] M(anibus) [S(acrum)। / [CL] ODIA / [C]QMPS[E] / $/[\mathrm{A}] \mathrm{NN}$ (orwm) XL[...] $/ 5$ [H(/c) S (ita)] E (st) S (it) T (ibi) [T (erra) L (evis)।

\section{/ [CLO]DIA F[VSCA ?] / MATER}

"Consagrado aos deuses Manes. Aqui jaz Clódia Compse, de quarenta e .... anos. Que a terra te seja leve. Clódia Fusca (?), a mãe."

VALE, A. de L. e, "Os Coitos", Beira Alta, 17(2-3), 1958,243-254; "Antiguidades romanas dos Coitos", Beira Alta, 19 (3-4), 1959, 79-80.

Infelizmente apenas pudemos dispor de testemunhos fotográficos, o que dificultou a leitura de determinados passos. O cognome materno Fusca é, portanto, apenas uma hipótese. Outras poderão ser sugeridas, mas o espaço disponível não parece aceitar um nome muito maior. Apesar de muito mutilada, a ara não perdeu a sóbria beleza de outrora, que alguns frisos, ainda visíveis, teimam em mostrar. A ordinatio é perfeita, mas nota-se uma variação na dimensão dos caracteres. Da primeira para a última linha parece haver uma redução no tamanho das letras, do tipo capital actuária. A invocação aos deuses Manes e a paleografia apontam-nos como cronologia provável a segunda metade, ou finais, do séc. I da nossa era. Que seria uma família detentora de um sólido património, assim o deixa supor o tipo de suporte utilizado.

O tempo é um agente corrosivo por excelência, ao qual nada escapa, nem a pedra, que recebe uma mensagem que se deseja eterna, nem a memória dos homens. Assim se compreende que a reutilização desta ara funerária não levantasse, para os novos dedicantes, quaisquer condicionantes de profanação. Decorridos cerca de dois séculos, quiseram Cláudia Gerôncia e Valério Hereniano, na última homenagem a seu filho, mostrar o grande apreço que lhe tinham. A pedra mais fina buscaram. Mas parece ter sido difícil encontrar, naqueles tempos de crise, o material pretendido. De mármore, apenas se lhes terá oferecido uma antiga ara epigrafada em uma das suas faces.

E foi dela que se serviram.

\section{Inscrição em prosa}

Como é habitual nos carmina epigraphica, a sequência métrica é antecedida pelos dados em prosa relativos ao defunto e, eventualmente, aos dedicantes, como no presente caso (Est. II, B). 
[D\{iis) M (anibus)] S (aerum) / IVVENTIO / ANN \{orum) XL Vili (iquadraginta octo) CLK $\{$ dia) CERONTIA / ET VAL\{́erius) HERENIANVS F F L L (sfc) P \{lentissimo) / H (une) \{hederae) T(itulum) (hederae) ¥ (ecerunt) / VINCITVR HIC FATVS / SALWM SVB TARTARA / NOMEM (sic) HIC SEDIS HIC TERRA / HIC T[IB]I ÇTER[NA] [DO]MVS

"Consagrado aos Deuses Manes. A Juvêncio, de quarenta e oito anos. Cláudia Gerôncia e Valério Hereniano ao filho, modelo de piedade, fizeram esta poesia:

'Vencido aqui, está,o Fado; salvo, sob o Tártaro, o teu nome. Aqui o túmulo, aqui a terra, aqui tens a tua eterna morada" ".

Hae 1488; VAlE, A. de L. e, "Os Coitos", Beira Alta, 17 (2-3), 1958, 243-247 e "Antiguidades romanas dos Coitos", Beira Alta, 18 (34), 1959, 79-80; CARDOZO, M., "Uma interessante inscrição funerária", Beira Alta, 19 (2-3), 1959, 204-212. VAZ, J. L. L, Roteiro arqueológico do concelho de Viseu, 1987, 35; ENCARNAÇÃO, J. d', "Indigenismo e romanização na epigrafia de Viseu", Acto do I Colóquio Arqueológico de Viseu, 1989, 319-320 e 323 (foto); SANDERS, G., "Sauver le nom de 1' oubli: le témoignage des CLE d'Afrique et aliunde", Africa Romana, 1989, $66\left({ }^{2}\right)$.

Variantes: L. 3: CLA|\{dius) GerontIA \{nus) (HAE; Cardozo; Vale); L. 4: FFLLP (flamines perpetui).

\section{- Descrição do monumento e comentário paleogràfico}

Devido à sua extensão, o epitáfio acima apresentado foi gravado numa orientação perpendicular à da inscrição da face frontal. A tipologia do monumento alterou-se, não só por necessidade de um campo epigráfico mais vasto, mas também porque a arquitectura do sepulcro assim o exigia. Esta placa deverá ter pertencido à parede de um $\mathrm{j}$ azigo, noção que também encontra apoio linguístico no próprio texto (utilização de sedes e domus).

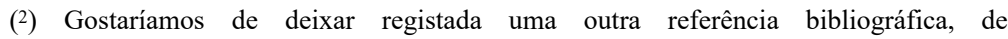
cuja informação não pudemos dispor, por o estudo não estar ainda publicado Silva, Armando Coelho Ferreira da, Aditamento ao Corpus das inscrições romanas de Viseu: a epígrafe do Couto de Baixo (Viseu), comunicação apresentada no II Colóquio Arqueológico de Viseu, Viseu, 26-29 de Abril de 1990.

Conimbriga, 31 (1992), 155-172 
A placa, pela sua ornamentação, quase inexistente, não suscita reflexões demoradas. $O$ pouco trabalhado que apresenta não tem um carácter próprio, ou seja, os contornos que lateralmente emolduram o texto mais não são que os frisos delimitadores do capitel e da base da primitiva ara.

Maior atenção exige o comentário paleogràfico. A impressão que a ordinatio nos causa é a de uma simetria aparente. Este resultado evidenciará a pouca mestria do ordinator ou exemplificará-opinião esta mais do nosso agrado - o tipo de trabalho efectuado na oficina epigráfica de que proveio. Questão de momento insolúvel e que só o conhecimento de outros monumentos, comprovadamente oriundos do mesmo atelier, poderia esclarecer.

O tratamento dos caracteres actuários está já bem longe da elegância posta, dois séculos antes, no epitáfio de Clódia Compse (?). A irregular da dimensão das letras deixa transparecer uma certa despreocupação com a harmonia do conjunto. Mas facilmente se adivinha um eixo que centraliza o texto e cujas extremidades, superior e inferior, são, respectivamente, o $\mathrm{N}$ de Juventius e $\mathrm{E}$ de sedis (uma vez que o texto se encontra mutilado no espaço imediatamente abaixo desta última). Nas 11. 2, 3 e 4 são perfeitamente visíveis linhas de pauta, que poderiam ter existido na restante sequência, mas que a fotografia não deixa perceber. Caracteres maiores ao lado de outros mais pequenos, até quando se trata do mesmo (cfr. os dois $\mathrm{W}$ de saluum, 1. 6); o espacejamento mais amplo do início da frase a contrastar com a concentração do seu final, onde a última palavra parece não caber (1.2); bem como a existência de uma margem mais larga à direita são alguns dos elementos que a fotografia permite observar e que contribuem para uma sensação de "atravancamento".

As hederae que encontramos na quarta linha a separar as iniciais HTF, e que por isso funcionam como puncti, denotam um ténue cuidado estético. Mais uma vez a perfeição não terá sido uma das qualidades que presidiram à feitura de tão breve rasgo artístico. A simples observação imediata mostra-nos que não há uniformidade no modelo da folha ou da haste, mas antes uma semelhança, que se frustra por completo no desenho do caule que liga as hederae geminadas.

Da primeira linha do texto podemos apenas discernir a parte inferior de um $\mathrm{S}$, que julgamos pertencente à sigla DMS, já que, se se tratar de um gentilicio, seriam ainda visíveis os arranques de, pelo menos, uma ou duas letras, ¡mediatamente anteriores. 
Merece particular referência a sequência FFLLP, que consideramos ser a maior dificuldade para uma interpretação cabal da epígrafe. A tradução que apresentamos é apenas uma proposta, que poderá, eventualmente, ser corrigida. Como nos foi sugerido pelo Professor Doutor José d'Encarnação, teria havido, por parte do lapicida, uma leitura incorrecta da minuta. Estaríamos perante dois dativos. A última inicial estaria bem lida e seria a primeira consoante do adjectivo pius,-a,-um, na forma superlativa pientissimo. A antecedê-la estaria o substantivo filio, esquecido o $\mathrm{O}$, os segundos F e L seriam dois I. Que o lapicida (ou até mesmo o ordinator) teria, pelo menos, um deficiente conhecimento da língua comprova-o, na 1.7, a grafia do substantivo nomen, com um $\mathrm{M}$ final. Que ele tenha incorrido em lapso tão aberrante, como parece indicar a forma FFLLP, não é lícito afirmá-lo com toda a certeza.

\section{- Comentário histórico}

A primeira linha de texto que até nós chegou informa-nos de que o defunto se identificava apenas com um nome, Juvêncio, pelo que tudo indica. De origem tusculana Juventius aparece geralmente na onomástica latina como gentilicio $\left(^{3}\right)$. De facto, Kajanto, na sua lista de cognomina latinos, não o regista $\left({ }^{4}\right)$. Estamos, portanto, perante a apropriação de uma forma gentílica por um cognomen, para o qual não encontrámos paralelo na Península. A sua etimologia é clara e prende-se com a raiz iuv -, que aparece em palavras como iuvenis, -is (“jovem”) e iuventas, -utis (“juventude"). Com este nome quiseram seus pais, por certo, desejar-lhe uma vida cheia de felicidade, como deve ser, em regra, a dos jovens. As Parcas não traíram por completo as promessas que tal nome encerra, pois deixaram viver Juvêncio quase cinquenta anos. O facto de ele se identificar apenas pelo cognome, leva-nos a pensar que se trataria, talvez, de um escravo ou de um indígena. Não será, contudo, de desprezar uma outra justificação para o emprego de um só nome. Poderá tratar-se de uma alcunha familiar. Em abono desta última interpretação podemos evocar o cognomen da mãe, Gerontia.

Curiosamente, mãe e filho apresentam cognomes falantes. Não nos parece totalmente despropositado uma mãe chamar-se "Anciã" e ter um filho que dá pelo nome de "Jovem". Ainda hoje, principalmente nos

O Cic. Pro Plane. 8. 19.

$\left(^{4}\right)$ Kajanto, L, The Latin cognomina, Roma, 1982 (reimpr.). 
meios rurais, um afilhado chama ao seu legítimo padrinho "padrinhonovo" e aos pais deste "padrinho-velho" e "madrinha-velha" ${ }^{5}$ ).

Ambos os dedicantes se identificam com dois nomes, o gentilicio e o cognome. Por norma, a mulher romana era denominada apenas por estes dois elementos. A ausência do praenomen no caso do marido é normal, numa época em que ele perdera já o seu valor distintivo - dado que também aponta para a cronologia tardia da inscrição ( ${ }^{6}$ ). Os gentilicios usados são muito comuns entre os Romanos e bastante antigos. Assim, o nomen Claudius, $-a$, é de origem sabina e muito frequente na epigrafía peninsular $\left({ }^{7}\right)$. R. C. Knapp coloca-o em décimo segundo lugar entre os nomina mais frequentes na Hispânia ${ }^{8}$ ). Maior ocorrência na Península $\left({ }^{9}\right)$ tem, por seu lado, a gens Valeria (nome cuja etimologia se prende com o verbo valeo, "passar bem, ter saúde, ser poderoso"), que surge com uma certa regularidade em Conimbriga $\left({ }^{10}\right)$ e no conventus Pacensis $\left({ }^{\mathrm{n}}\right)$. No conjunto da epigrafía peninsular, Valerius, $-a$ é o segundo gentilicio mais corrente. Pudemos verificar que as duas gentes se encontram documentadas na região de Viseu $\left.{ }^{(12}\right)$.

Como se vê, estamos perante nomina perfeitamente latinos. O mesmo se passa com o cognome Herennianus, que no texto se apresenta grafado sem a geminação da nasal apico-alveolar - forma menos correcta, que não tem, necessariamente, de ser encarada como um erro de gravação; podia ser escrita desta forma pelo seu próprio portador.Trata-se de um exemplo da formação de cognomes a partir de gentilicios. Neste caso serviu de base o nomen Herennius - muito frequente, aliás, em toda a Península Itálica e trazido para as províncias com a imigração ita-

$\left(^{5}\right)$ Não aludimos no texto ao caso das designações senior, para o pai, e junior, para o seu filho, pois estamos perante um exemplo de mãe e filho.

$\left.{ }^{(}\right)$Thylander, H., Etude sur Uépigraphie latine, Lund, 1965, 77-81.

$\left(^{7}\right)$ CIL II, 1059, regista cerca de meia centena de exemplares.

$\left.{ }^{8}\right)$ Os dados estatísticos relativos aos nomina Claudius, $-a$ e Valerius, $-a$ foram recolhidos em KNAPP, R. C., "The origins of provincial prosopography in the West", Ancient Society, 9, 1978, 221.

$\left.{ }^{9}\right)$ CIL II, 1074-5, regista cerca de uma centena de testemunhos.

(10) Fouilles II, 225-6, aponta uma dúzia de casos.

(n) IRCP, 865, indica cerca de uma dúzia de exemplares.

(12) Valerius Reburrus (CIL II 411), Valeria Cattia (FE 71) e T. Claudius Sancius (CIL II 432). Seria interessante fazer uma análise mais minuciosa da expressão destas duas famílias na zona, estabelecer eventuais relações de parentesco, mas com isso estaríamos a afastar-nos dos objectivos do presente trabalho. 
liana $\left.{ }^{13}\right)$ - ao qual se juntou o sufixo -anus. Este denuncia adopção ou hereditariedade, quando associado ao gentilicio dos pais adoptivos ou dos progenitores do indivíduo. Era ainda usado no caso de escravos ou libertos, para indicar a pertença a determinada gens. Convém, no entanto, observar que os cognomes assim formados não eram muito frequentes nestes dois grupos sociais. A noção de dependência, que o sufixo encerra, com o decorrer dos tempos, deixou de existir para muitos falantes da língua. Não podemos, assim, afirmar com segurança que Valerius Herennianus estivesse ligado, por laços de qualquer tipo de dependência, a uma gens Herennia. Note-se, ainda, que Herennianus não é um cognome muito frequente no Império $\left({ }^{14}\right)$ : para a Península, o Corpus Inscriptionum Latinarum ( ${ }^{15}$ ) apenas regista cinco exemplares, a que as Inscrições romanas do conventus Pacensis juntam mais dois $\left({ }^{16}\right)$. Curiosamente, em Aguilar de la Frontera (Bética), documenta-se um Valerius Herennianus (CIL II1515 = ILER 245), sem que obviamente seja possível estabelecer quaisquer relações de parentesco entre este e o da epígrafe em consideração.

O cognome Gerontia aparece grafado com a gutural surda (como acontece com Cn. e C. dos praenomina Gnaeus e Gaius), indício provável da estereotipização da escrita epigráfica $\left({ }^{17}\right)$. É um cognome de origem grega, da família do verbo que significa "envelhecer", athenai, e do substantivo athenai, -athenai "velho".

A ausência de qualquer referência à filiação, a presença de onomástica grega e - de uma forma menos segura - a formação do cognome Herennianus fazem-nos pensar que se trata de libertos.

A utilização de um titulus ${ }^{(18)}$ como laudatio funebris terá surgido, por quanto sabemos, com os elogia Scipionum. No entanto, tornou-se,

(13) LASSÈRE, J.-M., Vbiquepopulus, CNRS, Paris, 1977, 180-181.

(14) KaJANTO, O. C., 148.

(15) CIL, II, 1084 (note-se que as inscrições 1332 e 1333 referem as mesmas personagens).

(16) IRCP 45 e 46.

$\left.{ }^{17}\right)$ O grafema G já se regista em latim desde o séc. III a.C., como informa Niedermann, M., Phonétique historique du latin, Paris, 1985, 9.

$\left.{ }^{18}\right)$ Titulus $\dot{e}$ o termo que mais aparece nos monumentos epigráficos para designar "inscrição poética" (SANDERS, G., "Sauver le nom de l'oubli: le témoignage des CLE d'Afrique et aliunde ", L'Africa Romana, Atti del VI convegno di studio Sassari, 16-17 dicembre, 1989, 43-44, nota 6). Foi este o sentido que adoptámos na nossa tradução, pois é o que nos parece mais apropriado ao contexto. 
durante séculos, uma prática quase exclusiva de uma plebe média e, principalmente, de uma elite de libertos ou escravos. De facto, nos três primeiros séculos da nossa era, as famílias senatoriais não figuram nas inscrições em verso $\left.{ }^{(19}\right)$. A este indício cultural do estatuto plebeu das presentes personagens junta-se um outro, agora de base linguística, presente na sequência métrica que encerra o epitáfio. Ao contrário do que se passa com a forma nomen, a grafia $d t$ fatum, com s final, não constituirá uma deficiente leitura da minuta. Sabe-se que a alteração do género originário do substantivo (neutro) é sintomática do empobrecimento a que estava a ser progressivamente sujeita a língua nos meios menos cultos $\left({ }^{20}\right)$. Em nosso apoio vem Petrónio, que, em trechos de linguagem coloquial do Satyricon, usa a forma masculina fa tus (21).

Estamos perante uma família de libertos, suficientemente afortunados para erigirem um mausoléu a seu filho e confiar ao mármore as suas últimas, mas as mais eternas, saudades. Tudo isso já o sabemos. É chegado o momento de reflectirmos sobre o aspecto mais particular e interessante — porque menos corrente na epigrafia latina - desta inscrição, o carmen.

\section{Inscrição em verso}

\section{- Carmina epigraphica}

Antes de nos debruçarmos sobre o valor literário do presente poema, o tema que desenvolve, bem como os particularismos linguísticos que patenteia, convirá fazer algumas reflexões de carácter geral, capazes de nos fornecerem uma visão mais ampla da representatividade do carmen epigraphicum (não apenas o funerário) na produção epigráfica do Império Romano.

$\left.{ }^{19}\right)$ Pikhaus, D., "Les origines sociales de la poésie épigraphique latine: $V$ exemple des provinces nord-africaines", AC, 50, 1981, 638.

$(20)$ J. Corell Vicent corrobora a nossa opinião sobre o estatuto plebeu desta família, quando informa que tanto domus como sedes se encontram quase sempre em epitáfios de pessoas de condição servil ou origem oriental ("El epitafio poético de L. Iulius Aptus (Mértola, Portugal)", Conimbriga, 27, 1988, 149, nota 24).

(21) Satyricon 42, 71 e 77. 
Dorothy Pikhaus fixa em cerca de 4100 o número total dos carmina ${ }^{22}$ ). Podemos acrescentar-lhe mais cem, como G. Sanders (23), sem contudo alterarmos as conclusões que podem tirar-se desta informação: face às cerca de 280.000 inscrições latinas, os carmina epigraphica mais não são do que, aproximadamente, $1,5 \%$ do seu total. Note-se que $60 \%$ desta poesia epigráfica é de origem pagã (2500) e os restantes $40 \%$ de produção cristã (1700). Quanto ao nosso poema, ele é, como se sabe, um carmen sepulcrale, tipo que representa $80 \%$ da produção pagã dentro do género. O hábito de escrever tituli métricos é, ainda, extensivo a todo o Império. Não obstante, a produção de todas as províncias representa, apenas, $1 / 3$ do total. É à província africana que cabe a maior fatia. À supremacia da África romana não terá sido de todo alheia a predilecção que por ela tiveram as filhas de Zeus e Mnemósine, distinguindo-a com autores notáveis como Terêncio (séc. II a.C.), Frontão de Cirta, Apuleio de Madauros (séc.II), Tertuliano e Cipriano de Cartago (séc. Ill), Arnobio de Sica e o seu discípulo, Lactâncio (princípios do séc. IV) e, três gerações mais tarde, o maior de todos, Agostinho de Hipona.

Face a estes dados, será caso para dizer que estamos a estudar uma raridade, principalmente no que se refere ao actual território nacional, onde, pelo que sabemos, os exemplares são raríssimos. Apesar do seu reduzido número, os carmes epigráficos revelam-se cheios de interesse, principalmente se são funerários, isto porque nos dão a representação cultural de uma emoção ${ }^{24}$ ), ou seja, não reflectem uma cultura, mas a expressão que dela quiseram dar, ou sentiram necessidade de dar, os seus agentes. Os epitáfios métricos trazem aos historiadores e filólogos contributos inestimáveis. São eles a matéria-prima do que costuma designar-se por "História dos Sentimentos", a história do homem, que, espontaneamente ou por pura convenção, se desnuda para a posteridade. Com esta última observação começámos já a abrir caminho para uma das questões a focar no decurso da análise pormenorizada do titulus dedicado a Juvêncio: a originalidade ou convencionalismo da poesia funerária.

Para os estudiosos da literatura latina interessa reflectir sobre o valor poético da composição em análise. Não devemos, contudo, procu-

(22) Pikhaus, D., o. c., 637.

(23) SANDERs, G., "Le dossier quantitatif de l'épigraphie latine versifiée", AC, 50, 1981, 717.

(24) SANDERS, a c., 1981, 719-720.

Conimbriga, 31 (1992), 155-172 
rar nos autores anónimos dos carmina epigraphica novos Catulos, Virgilios ou Horácios, pois as nossas expectativas resultariam frustradas.

Com esta advertência ficamos, desde já, preparados para explorar, com a objectividade que a um texto poético — independentemente do seu maior ou menor valor literário - é permitido atribuir, o presente epigrama. Antes, porém, teceremos algumas observações relativas à génese dos carmina.

Entramos, pois, na questão que mais dificuldades levanta e para que, na maioria dos casos, apenas podemos aventar hipóteses. Quando nos interrogamos se o dedicante foi, ou não, o autor de determinados versos, estamos, implicitamente, a levantar a questão da sinceridade do seu conteúdo.

Assim, alguns estudiosos defendem a teoria dos catálogos, os quais se encontrariam nas oficinas epigráficas à disposição dos clientes, que escolheriam um poema do seu agrado. A autoria desses carmina epigraphica também pode ser atribuída a poetas locais. Diversas vozes se levantam contra estes pontos de vista, defendendo que os familiares do defunto teriam a educação necessária para comporem, eles próprios, um epitáfio métrico $\left({ }^{25}\right)$. Há cinco anos, Dorothy Pikhaus apresentou um estudo na revista Euphrosyne da Faculdade de Letras de Lisboa em que se ocupa, mais desenvolvidamente, desta polémica $\left({ }^{26}\right)$. Parecem-nos pertinentes as objecções que aí apresenta à teoria dos catálogos. Como contrapõe a autora, é excessivamente cómoda a hipótese dos carmina modelo, pois ficariam eliminadas todas as questões sobre o autor do poema e do dedicante, negando a este toda a proficiência requerida para a elaboração de um, muitas vezes humilde, poema. Consequentemente os carmina deixariam de reflectir a cultura individual do dedicante, para apenas se fazerem eco dos reportórios da oficina epigráfica ou das antologias de poetas profissionais. São vários os pontos frágeis da hipótese dos catálogos. Assim, notou-se que a existência de poemas idênticos, originários de regiões distantes, era rara. A fraseologia similar encontra-se, com frequência, em inscrições da mesma cidade ou re-

(25) Para a bibliografia fundamental acerca de esta polémica, cfr. CHEvaluier, R., Épigraphie et littérature à Rome, Faenza, 1972, 50, nota 267.

(26) "Literary activity in the provinces: the carmina latina epigraphica from Roman Africa (Ist-VIth century)", Euphrosyne, 15, 1987, 174-178. Aqui são referidos como principais defensores da teoria dos manuais F. Le Blant, R. Cagnat, H. Focillon e T. Tolkiehn. Outros dois estudiosos de renome tomaram uma posição igual à da autora: CHEVALLIER, O.C. , 50; SANDERS, O. C., 1989, 49.

Conimbriga, 31 (1992), 155-172 
gião ${ }^{(27)}$. Sustentando a ideia da divulgação de antologias e manuais por todo o vasto império romano, Cagnat $\left({ }^{28}\right)$ postula a existência de uma uniformidade cultural difícil de aceitar, mesmo no mundo de hoje. Em favor da composição individual refira-se que, entre os Romanos, a cultura era um fenómeno "popular" (entenda-se não elitista). Não somente em Roma, mas em todo o Império, o povo romano estava impregnado pela poesia dos elegíacos $\left({ }^{29}\right)$. Também os numerosos erros de prosódia e gramática, que muitos dos epitáfios apresentam, contradizem a existência de modelos, cuja característica mais evidente seria a correcção. Significativo se torna o facto de a tese dos manuais não parecer, aos arqueólogos e historiadores eclesiásticos, adequada ao estudo dos carmina cristãos. Como observa D. Pikhaus no referido estudo (177-178), for it would be rather absurd to assume, in order to write a short poem an Augustine, a Paulinus of Nola or an Ambrose would have needed the help of an anthology from the stone-cutter's workshop.

Quer optemos pela sinceridade dos carmes, quer simpatizemos preferencialmente com as teorias que defendem o seu convencionalismo, em muitas das composições achadas, são inúmeros os intertextos com autores famosos da literatura latina.

No caso do epitáfio de Juvêncio, não nos parece ter havido a influência de um poeta latino em especial, que se possa determinar com exactidão. Ele reflecte, sim, uma concepção de morte com raízes muito fundas na civilização romana e que alguns autores clássicos também abordaram, como veremos mais adiante.

\section{- Métrica}

As quatro últimas linhas gravadas na lápide contrariam, por certo, a disposição original do texto, uma vez que só são metricamente entendíveis se arrumadas em dois versos. Esta alteração ter-se-á devido às dimensões do campo epigráfico, insuficientes para comportar uma sequência de dois hexámetros.

(27) LISSBERGER, E., Das Fortleben der römishen Elegiker in den Carmina Epigraphica, Tübingen, 1934,10-12; ZARKER, J. W., Studies in the Carmina Latina Epigraphica, Princeton, 1958, 115-121.

(28) Cagnat, R., Cours d'épigraphie latine, Paris, 1914, 286 (nota 1).

(29) Cf. a recensão crítica feita por A. Guillemin a LisSBERGER, E., o.c. , (Révue des Études Latine s, 1935, 404-406).

Conimbriga, 31 (1992), 155-172 
Apresentamos, de novo, o carmen, agora na sua forma correcta, para em seguida tecermos as considerações literárias e culturais que a sua escansão suscita $\left({ }^{30}\right)$.

Vincitur hic fatus: saluum sub Tartara nomen.

$-\quad-1-\quad-1-\quad \|-\cup v 1-\cup \sim 1-$
Hic sedis, hic terr (a), hic tib(i) eterna domus.

Costuma designar-se, incorrectamente, este par pelo nome de dístico elegíaco, formado por um hexámetro e um pentámetro. $\mathrm{Na}$ realidade, o segundo verso é, corn mais exactidão, um hexámetro constituído por duas tripodias catalécticas ${ }^{(31)}$.

No hemistiquio Vincitur hic fatus, a partição do hexámetro, quando da sua inscrição na lápide, respeitou a integridade da oração. O mesmo já não sucede no segundo hemistiquio, de que se sacrificou, no acto da gravação, o seu último membro, nomen, transferido para o início da linha seguinte (a terceira do carmen inscrito).

Quem quer que tenha escrito este epitáfio métrico - e nós acreditamos que podem ter sido os familiares do defunto - ou não era um bom conhecedor da norma clássica da língua, ou, de acordo com a pronúncia corrente, alterou a quantidade longa do E de eterna, que mais não é que a evolução do ditongo AE \{aeternus, - $a$, - um) (32).

Poderá ter havido por parte deste autor de versos, no entanto, uma certa preocupação estilística que não devemos menosprezar. A escansão do dístico mostra-nos a predominância de sons fechados, apropriados a um tema triste como o da morte. Assim, a reflectir a dor dos que ficam e choram o seu morto e a certeza de que este empreendeu uma viagem sem regresso, sobressai o uso dos espondeus, que enformam todo o primeiro hemistiquio do segundo verso e estão igualmente bem representados no anterior.

$\left.{ }^{30}\right)$ A pontuação do texto é da nossa responsabilidade.

(31) NougAret, L., Traité de métrique latine classique, Paris, 1986, 55-59.

(32) No campo, o ditongo monotongara-se já nos princípios do séc. II (como testumunha Varrão De lingua latina 5, 97). Esta pronúncia foi ganhando terreno e acabou por difundir-se na própria Urbe. Depois de um período bastante largo de vacilação, por volta do séc. IV, impôs-se a pronúncia monotongada em forma de e aberto, coincidindo, portanto, com o primitivo e. Comprovam a quantidade breve dessa monotongação do ditongo evoluções para algumas línguas românicas, de que damos dois exemplos do espanhol: caelum >cielo e praecone >pregón. (vd. MAJRINER Bigorra, S., Fonética latina, Madrid, 1967, 69-70 e 76). 
- Vida e morte: dois conceitos complementares

O homem concebe a sua vida de acordo com a crença que tem da morte. No presente epitáfio, é clara a noção que se tem desta última. Terminados os dias de luz, resta-lhe jazer num lugar profundo ( $\left.{ }^{33}\right)$, escuro ${ }^{34}$ ) e triste $\left.{ }^{(35}\right)$ - o Tártaro. Já remonta à tradição homérica a ideia do Tártaro (athenai) como um local profundo e tão distante dos Infernos como o céu da terra. Para esse local de suplício iam os criminosos ( $\left.{ }^{36}\right)$. Aos poucos, o conceito foi-se alargando, até ser confundido com os Infernos, na acepção de "mundo subterrâneo" $\left.{ }^{37}\right)$.

Nos Infernos corre o Letes. Quem beber dessas águas esquece, para sempre, a sua existência passada. O temor da outra vida, a vida das trevas, tem por detrás de si uma preocupação relativa a esta vida, a vida da luz. Receia-se a morte pelo possível apagamento da memória do defunto entre os vivos.

\section{- Apreciação literária}

É dentro desta linha de pensamento que se entende o significado do primeiro verso. As duas orações que o preenchem estão ligadas por uma relação de causalidade. Estamos, então, aptos a desfazer a impressão de impiedade, de rebeldia do homem face a forças superiores como as do destino, que transparece na afirmação da vitória do contingente (o homem) sobre o transcendente (o fado). É a própria terminologia do texto que nos permite apelidar de conflituoso o relacionamento do homem com o fado, pois conduz à supremacia (uincitur) daquele que se considera imune (saluum) ao olvido. Neste duelo desigual, as posições inverteramse: o vencedor transforma-se em vencido (fatus), o vencido em vencedor (nomen). Traduzindo as palavras do autor deste poema, diríamos: "O destino foi vencido porque o teu nome, mesmo nas profundezas do Tártaro, continua a brilhar, imune ao esquecimento da morte". O homem romano estava consciente de que se reduziria a pó $\left({ }^{38}\right)$ e que a morte física

(33) Tartara profunda ( Séneca, Phae. 951).

${ }^{(34)}$ Tartara nigra (Virgílio, Aen. 6, 134-135; Ovídio, Tristes 1. 2, 22).

(35) Tartara tristia (Virgílio, Aen. 4, 243).

(36) Homero, II. 8, 13-16, 478 e sqq. (cfr. PEREIRA, M. H. R., Estudos de história da cultura clássica. Volume I. Cultura Grega, Lisboa, 1988, 240).

${ }^{\left({ }^{37}\right)}$ GRIMAL, Pierre, Dicionário da mitologia grega e romana, (trad. port, de Victor Jabouille), Lisboa, 1992, 429-30.

${ }^{(38)}$ Hor. Carm. 4. 7, 16 (puluis et umbra sumus). 
era inevitável. Por isso o poeta não se coíbe de afirmar que o homem estará lá, sub Tartara. Mas a preservação da sua memoria entre os vivos dar-lhe-á uma luz capaz de ofuscar as trevas do Além e o apagamento que estas consubstanciam. Também na literatura encontramos a confirmação da crença na capacidade que o homem tem de inverter, em parte, o determinado. Virgílio foi um dos que, pela boca de Evandro, se fez eco dessa consciência: contra ego uiuendo uici mea fata $\left({ }^{39}\right)$.

Ecoa ainda, nos nossos ouvidos, a referência [tuus] nomen. A verdade que todas as pedras sepulcrais, desde os Romanos até aos nossos dias, confirmam é mesmo essa - o nome é o próprio sujeito, pois não há nada que melhor o individualize. Um poeta anónimo como este soube, contudo, dar o seu toque de novitas, quando tratou de forma pouco corrente $\left({ }^{40}\right)$ um tema tão querido ao ideário tradicional, como é a busca da imortalidade. De facto, na maioria das referências encontradas ao destino, o tom que perpassa é de um pessimismo epicurista, que considera imutável o destino $\left({ }^{41}\right)$. Também o estoicismo o concebe de igual forma. Séneca, sentenciosamente, afirmou: accusare fata possumus, mutare non possumus: stant dura et inexorabilia $\left(^{42}\right)$.

Mas voltemos ao nosso titulus. A repetição do advérbio de lugar hic, que confere uma estrutura anafórica ao segundo hexámetro, reforça o carácter circunstancial da morte, já adivinhado no verso anterior pela presença desse mesmo dítico. Isto é, a derradeira morada do Homem é definitiva, mas pode ser materializada sob a forma de um sepulcro. E aí que os seus familiares têm de dirigir-se para o visitarem. Falámos em "morada" e "visitar", o que é perfeitamente normal num culto funerário

(39) Virgílio,Aen. 11. 160.

${ }^{40}$ ) Mário Cardozo (1959) considera muito vulgar o modo como o tema da imortalidade aqui é abordada. Apresenta três exemplos para testemunharem a sua opinião. Note-se que isso apenas é verdadeiro no caso da inscrição CIL XIV 2852. As outras duas referências veiculam exactamente o contrário. Assim, em CIL V 7453, a expressão si potuisset uincerefata significa "se pudesse vencer os Fados", isto é, não se podem vencer. Identicamente temos em CLE 465 fati non uincitur ordo. Afirmando que "não se vence a ordem do Fado", fica implícito o carácter inglório de urna luta contra aquilo que o destino determinou.

(41) ABRY, J., "Fatalisme astral et "bonne étoile" dans les inscriptions latines de la Gaule (Narbonnaise et Lyonnaise)", La langue des inscriptions latines de la Gaule. Actes de la table-ronde tenue au C.E.R.G.R. les 6 et 7 octobre, 1988 (Université de Lyon III), Lyon 1989, 87-97.

(42) Sén., Dial. 12.4, 1. 
em que se ofereciam alimentos e bebidas aos mortos ( $\left.{ }^{43}\right)$. Encontraram-se, mesmo, alguns sarcófagos com o interior esculpido em forma de casa $\left({ }^{44}\right)$.

Decorridos quase dezassete séculos, ficou perdido o conhecimento desse "aqui", tão vincado no epitáfio. A tipologia do monumento epigráfico é o único elemento que nos pode informar sobre a configuração da sepultura usada, ao que tudo indica, um jazigo.

Do ponto de vista estilístico, o autor do carme evidencia um certo gosto pela redundância, que a anáfora já deixara transparecer e que os substantivos domus e sedis reforçam, pois num contexto de morte têm o mesmo significado. Esta sinonimia é clara não só na epigrafia $\left({ }^{45}\right)$, como também na literatura $\left({ }^{46}\right)$.

A referência ao pronome pessoal, na segunda pessoa do singular, não tem apenas um valor sintáctico-morfológico, denunciador de uma construção do verbo sum (na forma est) com dativo (significa “ter"). Pretende-se também apresentar, de forma clara, o objecto do carinho que o epitáfio testemunha. E a um tu que esta promessa de eternidade se dirige. E esse tu que domina todo o poema, uma vez que se subentende na restante composição ${ }^{(47)}$. E nesse tibi que se materializa toda a emoção de um poema formado por uma série de motivos recorrentes nos epitáfios. Ao Fado, ao Tártaro e à domus/sedis junta-se, agora, um outro, a Terra. A ausência de qualquer adjectivo a qualificá-la torna mais ambígua a sua acepção. Será a Terra mater ou a pátria? Talvez signifique apenas o lugar de repouso $(48)$.

Juvêncio, enquadrado nos valores tradicionais de um Império que dentro de pouco tempo se desmembraria, foi bafej ado pela providência do acaso. O seu nome chegou ao limiar do século XX e, graças ao gosto de uma época e dos seus progenitores, coroado de forma singular.

(43) BRELICH, A., Aspetti della morte nelle iscrizioni sepolcrali dell' Impero Romano, Budapeste, 1935, 9.

(u) Veyne, P., O Impèrio Romano, in ARIÈs, Ph. e DuBy, G. (eds.), História da vida privada, vol. I - Do Império Romano aoAno Mil, 1990, Porto, 211.

${ }^{(45)}$ Sedis aparece associado também ao adjectivo aeternus, $-a,-u m$, o que torna mais notoria a sua identificação com domus. Ex: ILER 5789, ICERV 294, CIL III 124, CIL VI 6314 e 11436, CIL Vili 6360.

${ }^{(46)}$ Vixg.Aen. 6. 371.

${ }^{\left({ }^{47}\right)}$ fatus (tuus), nomen (tuum), hic (tibi) sedis, hic (tibi) terra.

(48) BRELICH, o.c. 38. 
EsT. I

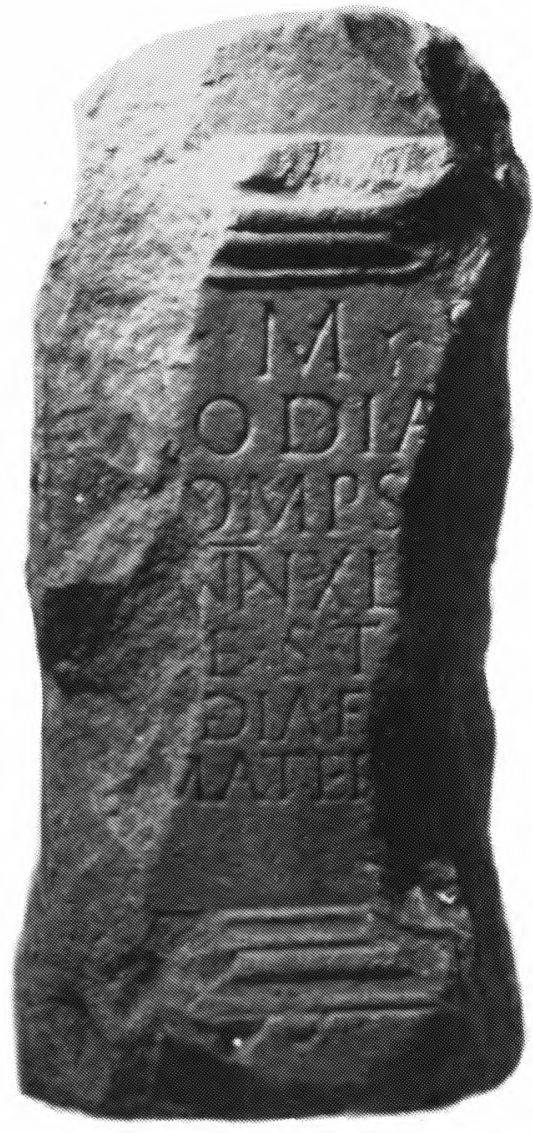

A

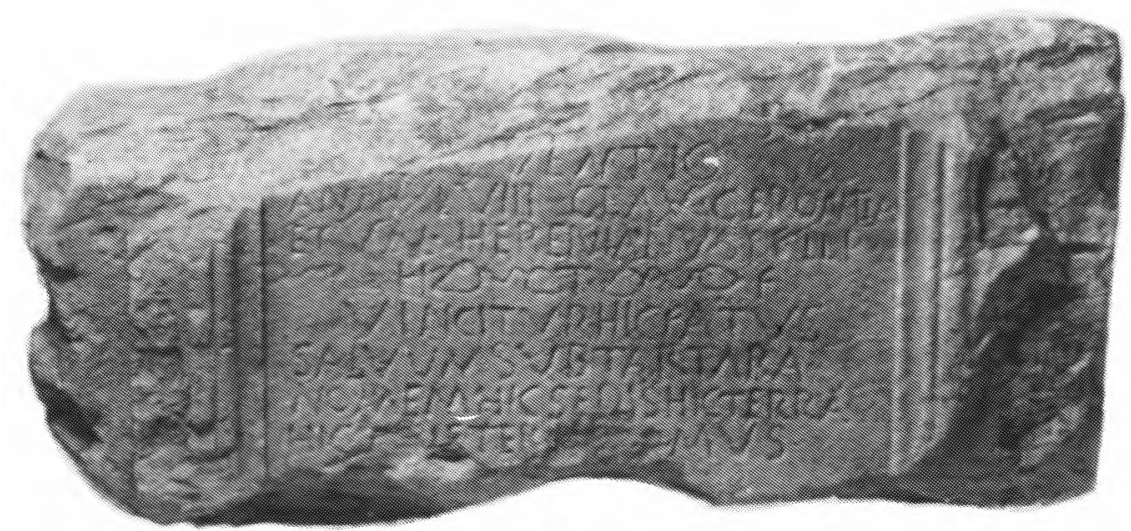

